\title{
Capítulo 1 Pensar la figura del perdón desde el daño atroz
}

\author{
Ángela Milena Niño Castro
}

La figura del perdón goza actualmente de una vitalidad política indiscutible. En buena parte, ello obedece al lugar privilegiado que se le concede como una alternativa necesaria para salir de recrudecidos ciclos de violencia. En la legislación colombiana, aparece la exigencia reiterada de pedir perdón o disculpas a las víctimas, como se señala en la Ley 975 de 2005, en la Ley 1448 de 2011 y en la Ley 1592 de 2012. A diez años de esta incursión del perdón en los procesos de justicia transicional en el país, con más de 1700 peticiones de perdón, surgen innumerables dudas e incertidumbres: ¿el perdón representa una alternativa valiosa para una comunidad política marcada por el daño atroz? Y si lo es, ¿bajo qué términos debe plantearse una vez ingresa a la esfera jurídico-política?

El presente capítulo plantea las difíciles tensiones que enfrenta el perdón en el contexto jurídico-político, en especial destaca, la posibilidad de pensar el perdón desde la perspectiva del daño atroz, cuya ocurrencia implica un crimen contra la posibilidad misma de perdonar. Se plantea que en contextos de daño atroz se requiere emprender procesos amplios y colaborativos de reparación moral, en virtud de los cuales el perdón puede aparecer nuevamente como una posibilidad moral importante para restituir la dignidad y estima moral de las víctimas, el agresor y la comunidad. 
La figura del perdón en contextos jurídico-políticos ha ganado un lugar privilegiado. En parte ello obedece a que las peticiones de perdón públicas, a las víctimas, se consideran alternativas valiosas para superar ciclos de violencia recrudecida. En Colombia, a partir de la Ley 975 de 2005 de Justicia y Paz, aparece entre las medidas de satisfacción y reparación simbólica a las víctimas de nuestro prolongado y desastroso conflicto armado, el ofrecimiento y la petición de perdón público. En la misma línea, están la Ley 1448 de 2011 y la Ley 1592 de 2012 que señalan la exigencia de ofrecer disculpas como un acto que restablece la dignidad de la víctima, la de sus familias y sus comunidades ${ }^{1}$. En estas tres leyes se considera, por una parte, que la reparación integral de las víctimas debe involucrar, entre otros, procesos en que los ofensores muestren arrepentimiento, comprensión de la atrocidad de sus hechos, promesa de no incurrir nuevamente en acciones violentas, voluntad de reparar a sus víctimas y la petición de perdón o disculpas. De otra parte, el perdón y la disculpa aparecen frecuentemente relacionados con los procesos de reconciliación y consolidación de la paz. En ese sentido, parece indicarse que una sociedad reconciliada requiere necesariamente involucrarse en procesos de perdón. De allí que desde la aparición de las mencionadas leyes, las ceremonias y peticiones públicas de perdón proliferan entre aquellos que se acogen a sus beneficios.

A la par, no es de extrañar el caudal creciente de investigaciones y debates que actualmente tienen lugar sobre el perdón, el arrepentimiento, la reparación y la reconciliación, en teología, literatura, ciencia política, derecho, sociología o psicología. Sorprendentemente, en filosofía, la reflexión sobre estos temas ha sido más bien escasa, aunque en fechas recientes ha adquirido creciente volumen y dinamismo, lo que demuestra su estricto valor filosófico y su aporte fundamental. Esta vitalidad en ascenso del perdón, hace necesario preguntarse si, a diez años de las mencionadas medidas de justicia transicional, con más de 1700 peticiones de perdón, ¿el perdón representa una alternativa valiosa para una comunidad política marcada por el daño

1 Es importante subrayar que las últimas leyes reemplazan la palabra perdón por el término disculpa. 
grave y atroz? Y si lo es, ¿bajo qué términos debe plantearse una vez ingresa a la esfera jurídico-política?

El presente capítulo se aproxima a las mencionadas preguntas, situando el problema al margen de cuestiones sobre la autenticidad o posibles beneficios terapéuticos del perdón. En su lugar, plantea la reflexión sobre el perdón desde la perspectiva de la reparación moral. Se trata de pensar el perdón en el marco de procesos morales que pretenden responder al daño. Desde dicha perspectiva, se defiende el lugar del perdón entre agresor y víctima como parte importante de los procesos de justicia restaurativa. Ahora bien, sin negar el valor moral del perdón, es necesario pensarlo desde la ocurrencia del daño atroz, que constituye un crimen contra la posibilidad misma de perdonar. En otras palabras, el perdón es una alternativa valiosa para restaurar y reparar las relaciones morales, pero una vez ocurre el daño atroz la posibilidad misma de perdonar es minada. Por tanto, se afirma que responder justamente al daño grave requiere emprender procesos amplios y colaborativos de reparación moral, en virtud de los cuales el perdón puede aparecer nuevamente como una posibilidad moral importante para restituir la dignidad y estima moral de las víctimas, el agresor y la comunidad.

En este orden de ideas, en un primer momento, se señalarán algunas tensiones que enfrenta el perdón en contextos jurídico-políticos y las razones para abogar por la presencia del perdón en dichos contextos desde un enfoque de la justicia restaurativa. En un segundo momento, se mostrarán las dificultades de pensar el perdón desde la perspectiva del daño atroz. En respuesta, se propone pensar el perdón en el marco de procesos amplios de reparación moral, en los cuales podría surgir un perdón moralmente valioso.

\section{El perdón en escenarios jurídico-políticos}

En los procesos de justicia transicional, se invoca frecuentemente la figura del perdón, especialmente del perdón jurídico que otorga el Estado a los infractores, como el modelo y la alternativa para resolver conflictos violentos. Así mismo, se insiste en la importancia del perdón entre víctima y victimario como paso hacia la reconciliación. Pero la aparición del perdón en contextos jurídico-políticos está acechada por 
innumerables dudas y amenazas. Por mencionar solo algunas: las peticiones de perdón despiertan dudas sobre la veracidad de lo narrado y la sinceridad de los victimarios; a su vez, son acusadas frecuentemente como meras estrategias diplomáticas o más bien cosméticas; pensemos, por ejemplo, en los casos de líderes o agentes del Estado que piden públicamente perdón en acatamiento a una orden emanada de alguna instancia o entidad internacional. Asimismo, parece que las peticiones de perdón se debaten entre ser estrategias meramente judiciales amenazadas de convertirse en expresiones inauténticas o en actos de impunidad que reafirman el olvido de las víctimas y su sufrimiento. En estos casos, el perdón aparece como un trato o transacción que un Estado acuerda con los infractores de sus leyes para asegurar la pacificación y reconciliación de una sociedad fragmentada. Por supuesto, en la realidad nacional e internacional muchas peticiones de perdón fácilmente se encuadran en dichas descripciones, en las que el perdón aparece como instrumento al servicio de otros fines.

De otro lado, la figura del perdón puede generar cierto escepticismo sobre su lugar en los procesos de justicia, lo que en consecuencia podría implicar que el perdón es un asunto de segundo orden frente a, por ejemplo, la reparación material, justicia penal e incluso frente a otras formas de reparación simbólica. En este orden de ideas, podría afirmarse que el perdón no pertenece a la esfera de la justicia institucionalizada y, por tanto, las peticiones de perdón no pueden hacer parte del marco de sanciones y obligaciones que impone el Estado a los agresores. Así, debido al carácter incierto de los procesos de perdón, a la imposibilidad de constatar la sinceridad del victimario y la disponibilidad de la víctima, tendrían que considerarse las peticiones de perdón como actos importantes, pero no definitivos para redefinir los términos de una sociedad que, como la nuestra, pretende salir de una espiral de violencia.

Además de las dudas y acechanzas que surgen frente a las experiencias y prácticas del perdón en la esfera jurídico-política, parece que existe otra serie de tensiones inherentes entre, por un lado, el perdón y la justicia y, por otro, entre el perdón y la política. En efecto, el perdón y la justicia parecen términos opuestos. Mientras el perdón estaría más asociado con la benevolencia y la compasión frente al culpable, la justicia estaría más relacionada con la pena y el castigo del ofensor. 
Generalmente, consideramos que la respuesta más adecuada al daño es la justicia y no el perdón, pues el daño exige acciones compensatorias o correctivas como las que ofrece la justicia.

Como señala Margalit (2004), el daño o la ofensa han sido históricamente relacionados en Occidente con la imagen de la deuda. De manera que hacer lo correcto o hacer justicia a quien sufre injusticia ha implicado en gran medida saldar una deuda, ya sea dando a alguien algo debido o devolviéndole aquello de lo que injustamente ha sido despojado. De allí que nuestra comprensión de la justicia ha quedado de manera definitiva ligada a una concepción correctiva y compensatoria.

En líneas muy generales, una concepción correctiva de la justica parte del reconocimiento de un conjunto de orientaciones morales o derechos básicos que son acordados por una determinada comunidad para todos sus miembros (para justicia restaurativa, véase Walker, 2006a). La ofensa o el daño consistirían, desde esta perspectiva, en desconocer a alguien el debido cuidado y atención que los acuerdos morales básicos señalan. Por ello, obrar con la justicia debida ante quien sufre un daño consiste principalmente en corregir el desvío o fallo en el cumplimiento de los acuerdos y derechos pactados. Ello implica remediar aquellas interacciones que no responden a los criterios de reciprocidad y responsabilidad reconocidos por los estándares básicos compartidos, principalmente a través del castigo del infractor según un tratamiento proporcional al daño infligido a la víctima. A la vez que implica compensar a quien sufre, pues la dirección básica de la justicia correctiva será restaurar el orden previo al daño con el propósito de reafirmar el estándar moral básico o los derechos básicos.

A diferencia de la justicia correctiva, el perdón desborda los límites del intercambio y la proporcionalidad entre la ofensa y el castigo; parece permanecer heterogéneo a la esfera de la justicia para mostrarse como un acontecer absoluto e incondicionado. En efecto, como afirma Derrida (2003), el perdón se resiste a la lógica del intercambio que en cierta medida impregna el lenguaje de la justicia. No se pide perdón como forma de compensación o de restitución. Al contrario, recurrimos al perdón cuando ocurre lo irreparable e imperdonable.

Así pues, la condición del perdón está en la raíz misma de su imposibilidad. Baste pensar en las razones que pueden conducir a una víctima 
a perdonar a quien le ha humillado o despojado de todo: sus posesiones materiales, sus seres queridos o significativos, sus horizontes morales y de sentido, su integridad psicofísica, incluso de su propia dignidad. En el fondo descubriremos que aquí no hay razón, motivación o justificación que pueda explicar el acto de quien perdona. Ni la presencia del arrepentimiento puede dar sentido al perdón, pues ello significaría que quien se arrepiente impone como obligación el perdón, de tal manera que la culpa y el arrepentimiento del ofensor se convertirían en ocasión para el perdón otorgado por la víctima. A diferencia de ello, en el acto de quien perdona hay algo de absoluta gratuidad e incondicionalidad, es un don que no depende de los actos o voluntad del ofensor.

Igualmente, el perdón escapa a la lógica de la proporcionalidad entre el daño y el castigo. Si bien es cierto que no todo daño es igual, de ello no se sigue que el perdón esté asegurado de antemano por el grado de la ofensa, como si solo se perdonaran las ofensas veniales y las ofensas graves exigieran castigo. Es más, advierte Derrida, justamente son las ofensas graves las únicas que merecen ser perdonadas, pues las otras pueden ser excusadas o disculpadas. Tampoco existe medida en el perdón, el perdón es absoluto. No se perdona todo aquello que fue castigado y se deja sin perdón lo no expiado. Se puede perdonar al ofensor y aún en ese caso exigir que sea castigado; pero también hay perdón incluso cuando el castigo está fuera de toda posibilidad. En otras palabras, el perdón no obedece a ningún cálculo; en esto se mantiene radicalmente aporético (Lefranc, 2005).

Justamente, advierte Derrida, es por el carácter aporético del perdón que no podemos enmarcarlo en los límites de las virtudes, de la ética o de la justicia institucionalizada. El perdón no puede ser pensado como una virtud o un hábito moral en el cual nos perfeccionamos hasta alcanzar el punto virtuoso o excelente del perdón. En cambio, el perdón aparece como una excepción que irrumpe en la sucesión o linealidad normal de los acontecimientos para introducir una instancia de reversibilidad del mal sucedido; no con la ilusión ingenua de deshacer el pasado, sino para hacerlo perder su filo venenoso (Arendt, 1958). Tampoco el perdón se presenta como el resultado de un juicio, pues no existen razones para aceptar perdonar, como es inaceptable pensar que podamos expresar el perdón en los términos de 
un norma universalizable. El perdón, recordemos, es un don absoluto. Por último, el perdón no puede ser administrado por los operadores de justicia, pues acontece solo en el marco de la relación interpersonal, entre la víctima y su agresor (Griswold, 2007).

El carácter apóretico o paradójico del perdón, en palabras de Mèlich (2012), muestra que permanece en una

(...) zona de indeterminación entre lo ético y lo religioso. El «sentido» del perdón habita en los «márgenes» de lo religioso, en una zona difusa entre la relación ética -una relación íntima, cara a cara- y la trascendencia o lo divino, «eso» que está más allá de los límites del lenguaje; «eso» que no se puede decir, pero que se puede mostrar a través del silencio; en definitiva, «eso» de lo que nada sabemos pero que creemos sentir. (p. 129)

Como señala Margalit (2004), el perdón como lo entendemos en nuestro contexto secular es prisionero del paisaje religioso. En el contexto bíblico existen varios modelos o imágenes del perdón. Margalit destaca especialmente dos de ellas, el perdón como borrar las faltas y el perdón como ocultación de las faltas. En el primero de los sentidos mencionados, el ofensor aspira a borrar las culpas y las cicatrices del daño, su ruego a Dios es deshacer el pasado: "borra mi culpa" (Ps. 51, 9); "lávame y quedaré tan blanco como la nieve" (Ps. 51,7) clama a Dios el salmista. Por su parte, en el segundo sentido, el ofensor ruega a Dios ocultar la falta, es decir, no tomar en consideración la ofensa: "Señor, Señor, si tuvieras en cuenta la maldad, ¿quién podría subsistir? Pero en Ti encontramos perdón" (Ps. 130, 3). En este último, el ofensor apela a la infinita benevolencia divina para reprimir la justa ira y la venganza que merece la ofensa. En el perdón como borrar las culpas hay un acto de olvido total; mientras que en el ocultar hay un acto de misericordia que restaura la intimidad con Dios. Sea que las culpas se borren o se oculten, Dios no está en la obligación de perdonar. Nuevamente aparece aquí el polo incondicionado del perdón que señala su carácter de gratuidad.

Una vez transitamos al campo jurídico-político, nos parece que aquel matiz ético-espiritual no tiene lugar en él. No tanto porque el perdón en su sentido religioso sugiera que solo Dios perdona, pues 
como señala Arendt, con la figura de Jesús se introduce el perdón en la esfera del trato de unos con otros, como una dimensión moral más de las relaciones humanas (Arendt, 1958). Más bien, es la lógica de la donación, la gratuidad, la benevolencia y de la relación que supone el perdón, la que no encaja en el contexto de una relación política, en donde a lo sumo debo respeto a los otros en vista de su dignidad como seres humanos. Presenciamos aquí, como diría Jankélévitch (1996), el enfrentamiento entre una moral de máximos, esto es, una ética hiperbólica del amor y la compasión y unas relaciones políticas que se expresan en términos de mínimos éticos, derechos y deberes.

En efecto, es bien conocida la división decisiva entre el campo de la moral sustantiva y la política que desde hace siglos goza de cierta aceptación en la reflexión política liberal. A nombre de la distinción entre la moral y la política, hemos podido pensar la organización de la comunidad política en términos puramente tales, sin miramientos a las creencias, cosmovisiones o perspectivas omnicomprensivas sobre la vida buena. Pese a que existen posturas que matizan la división entre moral, política y ética -las cuales no se discutirán en este escrito- es necesario sostener entre ellas un grado de distinción en orden a pensar las actuales democracias seculares, pluralistas, igualitarias y libres. Introducir el perdón con sus ecos religiosos y morales como un deber o virtud que se espera entre ciudadanos puede llegar a desconocer que los ciudadanos están en libertad de moldear su perspectiva sobre lo valioso y sobre el adecuado cuidado que esperan y otorgan a su prójimo.

Entonces, ¿cómo explicar las escenas globales de perdón?, ¿Por qué, pese a las tensiones que enfrenta el perdón en el contexto jurídico-político hoy, se presenta como una salida de la violencia grave y masiva? La respuesta apunta en dos direcciones. Por un lado, introducir el perdón como respuesta política a la violencia, estaría justificado por la incapacidad del Estado y sus instituciones de juzgar y castigar el daño grave y masivo. Ante el escenario de sistemas judiciales colapsados y desbordados por el número de crímenes, se recurriría al perdón de la sociedad y de las víctimas para integrar nuevamente a los ofensores. De otro lado, existe un corriente importante y creciente en el campo jurídico-político que apuesta por una perspectiva restaurativa para enfrentar la violencia. Se trata de comprender que superar 
experiencias masivas y sistemáticas de violencia depende crucialmente de la capacidad de las sociedades para restaurar las relaciones quebrantadas por los hechos atroces (Walker, 2006a). Para ello, resulta indispensable emprender una serie de acciones restaurativas, entre las cuales, aparecen el perdón y las disculpas.

Ahora bien, ¿cómo encara el enfoque restaurativo las tensiones que enfrenta el perdón en su incursión en la esfera jurídico-política? Por lo pronto, resulta fundamental su comprensión del daño y la redefinición de las formas en que se debe responder al mismo. Comprender el daño en su complejidad e indeterminación, le permite al enfoque reparativo transitar a una concepción ampliada de la justicia, replantear las relaciones entre moral, política y derecho y, finalmente, situar la importancia del perdón interpersonal en la escena política.

De manera muy sumaria, una de las características del enfoque restaurativo es su especial atención a las masivas experiencias de daño. Por ello, se entiende no solo que se trata de daños que involucran un amplio conjunto de víctimas, sino especialmente de daños incalculables e inciertos en sus alcances y efectos. Como señala De Greiff (2006), la justicia criminal fue pensada para responder a daños concretos y específicos a individuos que sufren o son víctimas de crímenes excepcionales y no frecuentes. Sin embargo, existen otros tipos de daños que afectan colectivamente, que se infligen de manera sistemática y prolongada y de los cuales resulta imposible calcular su magnitud. Responder a ese tipo de daños como si se tratará de casos individuales, al modo que lo hace la justicia criminal, es inalcanzable e insuficiente. De un lado, inalcanzable porque el sistema judicial no puede garantizar que millones de víctimas accedan a los mismos beneficios y reciban equitativo trato. Pero además, resulta insuficiente porque a diferencia del daño individual, los daños graves y masivos no son casos aislados y excepcionales, más bien producto de estructuras sociales y políticas injustas. Por tanto, en los daños masivos y graves está en juego más que la situación particular de los individuos; está también la necesidad de redefinir los contornos de la comunidad política. Para ello, será necesario emprender una serie de acciones que tengan por finalidad establecer relaciones civiles y sociales de nuevo cuño, afianzadas en la solidaridad, el reconocimiento, la responsabilidad y el mutuo respeto. 
En virtud de estos fines, cobran relevancia actos simbólicos como las intervenciones en el espacio público para guardar la memoria de las víctimas, los actos públicos de arrepentimiento y disculpa, entre otros.

Las acciones o programas de reparación así vistos parecen guardar poca relación con la justicia. En efecto, los días conmemorativos, monumentos, memoriales, actos de contrición, las peticiones de perdón, parecen ser manifestaciones menores o insuficientes frente a las formas punitivas o compensatorias de la justicia.

No obstante, con las acciones restaurativas se plantea una nueva perspectiva de la justicia. En palabras de De Greiff (2006), se trata de comprender que aun la justicia en sus versiones punitiva, correctiva y compensatoria requiere una serie de condiciones que ella misma no puede establecer; entre ellas, menciona la confianza cívica, el reconocimiento y la solidaridad. Por ejemplo, tendríamos que preguntarnos si la justicia criminal podría funcionar si previamente no nos hemos reconocido como individuos y ciudadanos con unas ciertas formas de vida y propósitos valiosos que pueden verse facilitados y obstaculizados por otros. Otro tanto podría decirse de la confianza cívica. Al respecto afirma el autor que el sistema legal parte de la excepcionalidad del daño; asume que el trato normal entre ciudadanos es de confianza y que la ley no tendría que intervenir o regular cada interacción humana. De otro lado, las consecuencias perseguidas por la justicia alcanzan fines políticos más amplios como fortalecer relaciones basadas en el respeto, la igualdad, la confianza y la solidaridad. Una concepción amplia de la justicia cuida tanto de las condiciones como de las consecuencias o fines perseguidos. En este sentido, las acciones restaurativas hacen parte integral de la justicia.

Finalmente, el enfoque restaurativo de la justicia redefine las relaciones entre derecho, política y moral. Las prácticas reparativas tienen la pretensión, entre otras, de transformar la economía, la política y el derecho; pues, como se mencionó, se comprende que el daño grave y masivo tiene causas y repercusiones que trascienden las vulneraciones concretas. De allí que se requiera establecer relaciones más fluidas e integrales entre la esfera del derecho, la política y la moral. Existen amplias e importantes corrientes actuales que apuestan a pensar las relaciones entre las mencionadas esferas, no trataremos de este tema 
ahora, en sí mismo complejo y extenso, baste señalar que las acciones reparativas plantean nuevas formas de pensar dichas esferas en tanto se persigue restablecer las relaciones entre ciudadanos y reivindicar la estima y autoridad de quienes han sufrido.

En el marco de esta concepción reparativa de la justicia, han aparecido gran cantidad de prácticas materiales y simbólicas. Como advierte Teitel (2003), los términos de la reparación son sumamente dilemáticos, ¿qué es justo reparar?, ¿a quiénes se debe reparar?, ¿a través de qué acciones y medios?, ¿por cuánto tiempo?, ¿quiénes deben ser los responsables de la reparación?, por mencionar solo algunas cuestiones. Las peticiones de perdón y disculpas, como prácticas de reparación, también tendrán que ser pensadas en toda su problematicidad.

En el caso colombiano, sorprende que la inclusión de la figura del perdón en las leyes como la Ley 975 de 2005 y la posterior figura de la disculpa en leyes como la Ley 1448 de 2011 y la Ley 1592 de 2012, haya generado tan escaso debate. Por nuestra parte, consideramos que uno de los dilemas que enfrenta la figura del perdón interpersonal en contextos jurídico-políticos surge una vez se atiende a la naturaleza del daño atroz.

En efecto, como se mencionó, la justicia reparativa responde especialmente al daño masivo y sistemático que destruye la vida, bienes y afecta corrosivamente las relaciones. Sin embargo, a nuestro juicio, se requiere pensar que también el daño grave significa la destrucción de mundo. Cuando un daño de dichas proporciones ocurre, las posibilidades de perdón están minadas. ¿Cómo, entonces, recurrir al perdón como medida de reparación cuando se han cometido crímenes contra el perdón?

\section{Destrucción de mundo: crimen contra el perdón}

Consciente acaso de las complejidades de la insuperable conflictividad que amenaza a toda relación humana, el pensador actual Charles Griswold (2007), asegura que en algún momento, casi todo el mundo ha agraviado a otro ser humano. Y también que alguna vez casi todos hemos ansiado ser perdonados. Correlativamente, según este autor, casi todo el mundo ha experimentado la amargura de una injuria 
que injustamente se le ha infligido. E, igualmente, que alguna vez casi todos nos hemos enfrentado a las dificultades que conlleva otorgar el perdón sofrenando el resentimiento y renunciando a la dulzura de una venganza.

El mencionado autor toma como piedra de toque de sus reflexiones el escenario paradigmático de aquella relación interpersonal en que un ofensor ha injuriado a un individuo concreto; aquel solicita a su víctima que le perdone, quien, si lo ve justificado, le otorga el perdón. Aquí, nos advierte, el resentimiento que experimenta la víctima normalmente está provocado por la acción agresora, pero se enfoca propiamente en la persona que la ha protagonizado; esto es, perdonamos al ofensor, no propiamente el hecho que ha cometido. Esta caracterización que aparenta ser banal, según el propio pensador, acarrea graves consecuencias en cuanto a las normas o criterios que definen el acto de pedir y recibir perdón. Entre ellas está el carácter esencialmente social del proceso y, en consecuencia, su condición inapelablemente moral. Social no significa aquí, advierte nuestro autor, que la sociedad haga el referido trabajo moral, al menos no en lo que respecta a este caso paradigmático.

Efectivamente, como quedó dicho en el primer apartado, ante daños graves o atroces el cuadro paradigmático que nos traza Grislwold debe ser radicalmente reformulado. Ante todo, se debe sacar de la penumbra en que aparentemente queda en dicho cuadro, el "tercer agente" (Corbí, 2012, p. 1). De lo contrario, la relación con el mal grave de este tercer agente, llámese individuo, grupo, organización, comunidad, o sociedad en general, podría fácilmente como tantas veces ocurre, soslayarse o preterirse, aunque nunca destruirse. Ante un daño atroz, pongamos para no salirnos de nuestro propio patio, el lamentable caso de la masacre de Trujillo, en el cual los victimarios trocearon con motosierra a sus indefensas víctimas aún vivas, nosotros como tercer agente nos horrorizamos y nos vemos forzados a exclamar “iesto no debería ocurrir!”. Aquí, el demostrativo "esto", no apunta solamente al hecho puntual que lamentamos, sino a todo tipo de atrocidades, no importa dónde o cuándo ocurran; parejamente, implica a todo ser humano que quiera vivir y actuar con estatura humana.

Siendo esto así, es indispensable intentar la caracterización, así sea someramente, del daño grave. Con tal propósito, iniciaremos destacando 
los rasgos generales que lo identifican. Seguidamente, probaremos determinar las principales clases y formas de vulneración que la injuria grave acarrea a sus víctimas.

Investigadores actuales identifican la gravedad del daño con la destrucción del mundo de la víctima (Carse \& Tirrell, 2010). Dentro de la reflexión filosófica hodierna, la idea de mundo ha venido adquiriendo indiscutible hondura antropológica. El filósofo alemán Martín Heidegger, en su obra inaugural define al hombre como ser-en-elmundo-con-los-otros. Los guiones que enlazan los términos de este concepto fundamental, son apenas un recurso gráfico para indicar que se trata de una única realidad compleja y dinámica. Con este concepto, Heidegger está dejando fuera de juego la concepción que la modernidad forjó del hombre como un ser desvinculado, esto es, como un Yo racional y libre que convierte en objeto de explotación a la naturaleza y al hombre mismo, todo en procura egoísta de beneficio; en esa búsqueda, según la concepción moderna, se encuentra y pacta con los demás hombres la convivencia social y las instituciones en las que todos los asociados logran su individual provecho.

Esa imagen antropológica ha dado pábulo al individualismo posesivo que espolia insaciable a los otros y a la naturaleza y que está en la raíz de las profundas crisis que ponen hoy en riesgo la viabilidad misma de la vida humana a nivel planetario. Ante semejante amenaza, una pléyade de pensadores actuales pertenecientes a distintos países y continentes, en línea con el pensamiento heideggeriano, baraja la triada de conceptos: entorno, medio y mundo. El entorno es el ámbito físico espacial dentro del cual se hallan los seres inanimados, en él las cosas guardan distinto tipo de relaciones: cercanía, lejanía, distanciamiento, aproximación, etc. Los seres animados, además de entorno, tienen un medio. El medio de un ser vivo es el conjunto de aquellas cosas o elementos que necesita para vivir y desarrollarse. Así, la luz, el sonido, el olor, el color, etc., son componentes básicos del medio de un gato; para un topo en cambio la luz, no es parte de su medio. El hombre, claro está que posee un entorno complejo y en imparable expansión, como que actualmente el entorno humano está ya alcanzando los confines del cosmos. Igualmente posee un medio, también de enorme complejidad y dinamismo, pues del medio del 
hombre actual hacen parte cosas como el grafeno, los cohetes o la estación espacial, solo por citar algunas, las mismas que no tenían lugar en el medio de los humanos de siglos pasados. Pero además de entorno y medio, el hombre posee mundo, o mejor, está abierto a, e implantado en, el mundo; en este sentido, el hombre es el único animal mundano conocido (Zubiri, 2006).

El mundo es el horizonte de posibilidades, de sentido y de valor, solo dentro del cual es posible y viable la vida humana. El hombre, a diferencia de los demás animales, es un ser forzado a proyectar su vida y a realizarse o florecer, con, a veces contra, pero nunca sin, los otros, indefectiblemente dentro de un horizonte de posibilidades y de sentido; de ahí que el lenguaje y en general todo el universo axiológico y simbólico no es algo añadido a su vida, sino algo que la constituye esencialmente. Por ese carácter mundano, el hombre es indisolublemente individual, social e histórico (Zubiri, 2006). No ocurre pues como pensó la modernidad que el hombre nace como un sujeto individual que gradualmente por el continuo comercio con sus semejantes $\mathrm{y}$ al ritmo de sus intereses y deseos se va haciendo social e intersubjetivo. Más bien ocurre lo contrario, pues son los otros los encargados de irle entregando, mediante la crianza y la educación, el sentido de lo humano y un estándar moral básico que han de regir sus acciones e interacciones dentro de un marco de confianza y de esperanzas compartidas. En esto se va humanizando y situando en un específico nivel de desarrollo histórico y social con sus horizontes concretos de sentido y valor. En este proceso de humanización, el lenguaje desempeña un papel basilar. En suma, si al hombre le amputamos su mundo, su comunidad, su lenguaje y sus valores, fracturamos su continuidad vital y amenazamos gravemente su existencia física, moral y espiritual.

Después de esta fragmentaria alusión al concepto antropológico de mundo, pasemos a indicar someramente qué se entiende por destrucción de mundo, que la investigación actual sobre el perdón hace sinónimo de daño grave. Cuando el agresor injuria gravemente a su víctima le destroza su mundo, esa matriz humana, solo dentro de la cual, según acabamos de mencionar, ha ido realizando su vida y florecido dentro de una trama de relaciones humanas fundadas en la confianza mutua y en la esperanza compartida. 
Cuando un mundo se hace pedazos, aquellos que fueron sus habitantes pierden toda orientación moral. Su lenguaje y acción empobrecen su sentido, su razón y sus motivos se oscurecen y las normas que antaño compartían quedan desprovistas de autoridad. Su sentido de seguridad y previsión desaparecen, como desaparece el marco de entendimiento donde las agresiones graves podían ser narradas y constatadas. (Carse \& Tirrell, 2010, p. 48)

La víctima experimenta la destrucción de su mundo como un cercenamiento de su propia vida que hace imposible la continuación y permanencia de su florecimiento vital. Una de las víctimas sobrevivientes del genocidio de Ruanda, testimonia esa destrucción cuando afirma:

De nada le sirve a un sobreviviente retornar al genocidio. Para quienes no lo sufrieron hay un antes, un durante y un después como momentos de una sola experiencia vital. Para nosotros, ciertamente hay un antes, un durante y un después, pero son diferentes vidas que se han fracturado para siempre. [Y agrega: (...)] a los sobrevivientes les cuesta creer que aún están vivos. Es decir, que sean los mismos seres humanos que antes fueron; en cierto modo, es un poco como ir halando la vida. (Carse \& Tirrell, 2010, p. 49)

Ese "ir halando" convierte la existencia de la víctima en vacío, desconfianza y desesperación, como lo denuncia uno de los sobrevivientes de holocausto judío: "Es imposible confiar en algo en un mundo que ha dejado de considerar al hombre como hombre, que constantemente "prueba" que uno ya no es un hombre. Uno empieza a dudar, comienza de dejar de creer en un orden del mundo donde Dios tiene un lugar definido" (Wiesenthal, 1969, p. 9).

El, o más bien los agresores, que perpetran un daño grave, lo hacen de manera calculada e ideológicamente "justificada" para dejar fuera de juego el más mínimo recato por la santidad de la vida de su o sus víctimas. Por ello, se ensaña en su cuerpo para vejarlo hasta el envilecimiento y se dedica expresamente a enturbiar los horizontes compartidos de valor y de sentido. En casos atroces como el genocidio, la violación o la tortura, la desaparición de estos horizontes da pábulo 
a la destrucción ciega y al envilecimiento. Desaparecen los anclajes morales de cualquier reconocimiento moral de la víctima, a la luz de los cuales el agresor se vea abocado a sentir sincero reconocimiento y arrepentimiento del mal causado. De manera idéntica, en la víctima desaparece la confianza en su propia valía moral al quedar trastocada su confianza en las normas que facilitan su fluidez en el lenguaje moral; "en tales casos, el proceso de perdón no puede cimentarse en un orden moral ya inexistente, tampoco existe la reserva de confianza que permita desarrollarlo". Al respecto la investigadora Claudia Card acota que palabras como "resentimiento", "ira" y aun "indignación” apenas si burdamente describen los rasgos de la respuesta moral a esas atrocidades. Resentimos los insultos, los robos y las injusticias, pero los crímenes atroces nos dejan sin palabras, cruelmente horrorizados y sumidos en la náusea. A su modo de ver el perdón no puede ser el antídoto contra el despojo de la palabra, el horror y la náusea (Card, 2002).

A primera vista, este contundente juicio de Card nos sorprende y desconcierta, especialmente si tenemos en cuenta el exitoso proceso de paz de Suráfrica, en que el arzobispo anglicano Desmond Tutu jugó papel destacado en llevar adelante procesos de perdón y reconciliación entre quienes habían protagonizado y sufrido los horrores del apartheid. Empero, esa sorpresa y desconcierto se mitigan, si atendemos a las heridas que el daño grave deja en las víctimas. Sobre el particular, el filósofo Daniel Philpott, considerando la hondura, anchura y gravedad de las heridas que causa en quienes padecen daño grave, distingue entre heridas primarias y heridas secundarias.

Las heridas primarias llegan a configurar hasta seis tipos, veámoslos someramente (2012, pp. 31-39).

- Violación de los derechos humanos de la víctima. La violación de los derechos de la víctima no es solo, según este autor, la definición de la injusticia política, sino que es también la vulneración de una de las dimensiones fundamentales del florecimiento humano, pues esa dimensión se llama respeto y dignidad garantizados por la ley.

- Daños infligidos a la persona de la víctima en su cuerpo, en su espíritu y en los cimientos mismos de la realización bumana: 
cobija una amplia gama de injurias que van desde la destrucción de la vida, la pérdida de los seres queridos, las violaciones, la tortura, el despojo de los bienes materiales hasta el envilecimiento de su etnicidad, su género, su religión, etc.

- Ignorancia e incertidumbre sobre las circunstancias y fuentes de la agresión. El clamor común de las víctimas sobrevivientes está enfocado al esclarecimiento de los autores y las circunstancias en que sus seres queridos fueron desaparecidos, torturados o asesinados y no cesa hasta tanto no retornen o al menos les sean entregados sus restos o algunas de sus pertenencias.

- La falta de reconocimiento de parte de la sociedad del sufrimiento de la víctima, debida a ignorancia, complicidad, miedo o simple indiferencia. En el remedio de esta falta juegan papel preponderante los ciudadanos y sus organizaciones, amén de las instituciones del Estado. Cuando no se produce, la víctima se ve condenada al anonimato, la vergüenza y la autoinculpación. Esta condena suele ser el pertinaz legado de regímenes despóticos y totalitarios.

- El papel victorioso que se suelen arrogar los perpetradores de crimenes atroces. Para estos, las atrocidades cometidas son consideradas formas de la reafirmación de un régimen a cuyo servicio se han consagrado fervorosa y brutalmente. Esa supuesta victoria no es sino el rostro de una "cultura de impunidad" que invisibiliza a la víctima y sus heridas, sumiéndola en la desconfianza, la desesperanza y el resentimiento.

- La sexta herida, en la enumeración de Philpott, como la anterior, afecta a los victimarios. En efecto, desde antiguo, al mismo tiempo que se reconoce que quien hace el bien y practica la justicia se ennoblece y acrecienta su humanidad, de igual forma, quien practica el mal se envilece y deshumaniza. El Sócrates platónico advierte en el diálogo Gorgias que quien comete el mal daña su alma, daño el peor que pueda sufrir un ser humano. Modernamente, abunda la documentación de casos de envilecimiento y destrucción de quienes cometieron crímenes atroces. Miembros de las SS, división 
del ejército nazi, integrada por la élite especializada en vejar y asesinar, eran atormentados por pesadillas pobladas de sus víctimas y sus sufrimientos; muchos de ellos se hundieron en el alcoholismo o cometieron suicidio.

Las heridas secundarias cuentan entre sus principales causas y desencadenantes a las heridas primarias ya reseñadas. Según Philpott, estas últimas generan una cadena de memorias, emociones, juicios y finalmente acciones que suelen tomar forma colectiva y conducir a guerras, genocidios, limpiezas étnicas, regímenes autoritarios de dudosa legitimidad (2002). Como puede verse, la expresión heridas "secundarias" aquí no significa de menor cuantía o algo por el estilo.

El propósito de este apartado era, aunque de manera muy abocetada, trazar los perfiles de la atrocidad del daño que el perpetrador causa en su víctima y que lo hace imperdonable. La quinta esencia de esa atrocidad, según quedó dicho, se consuma en la destrucción del mundo. Por ella, la víctima ve gravemente lesionada o en extremo destruida su integridad psicofísica; se hacen añicos o desaparecen sus vínculos sociales y afectivos. Las palabras de la comunicación cotidiana cambian de sentido incluso para adquirir significados perversos. La confianza en los otros y en el mundo y las esperanzas compartidas a que aquella da lugar quedan profundamente erosionadas casi hasta desaparecer. La continuidad del tiempo vital se fractura hasta el punto de llevar a la experiencia de vidas distintas e irreconciliables.

En definitiva, como señala Jankélévitch, existen crímenes contra la humanidad, "cuando un acto niega la esencia de un ser humano como un ser humano" (1996, p. 556) que son imperdonables y que son imprescriptibles por la magnitud del daño, pero especialmente porque han destruido el horizonte moral que hace posible y sostenible la orientación hacia el bien, sin la cual el perdón o el arrepentimiento pierden su sentido. En últimas, es por esta razón que el daño grave es en sí mismo y ante todo un crimen contra el perdón. En efecto, el daño grave agota las reservas morales que permiten al agresor reconocer el daño cometido como un crimen y anula un horizonte normativo en donde la víctima puede recuperar su valía moral. En estos escenarios atroces, todo parece indicar que el perdón no puede superar la violencia. 


\section{El perdón por venir}

Entonces, ¿cómo responder al daño atroz y cómo se puede pensar en una superación del mismo? Líneas atrás se mencionó que el enfoque restaurativo de la justicia considera que la reparación moral resulta una alternativa esencial, también se dijo que en dicho enfoque, el perdón tenía su lugar, pero parece que nos enfrentamos a una paradoja, una vez reconocemos que el daño atroz atenta contra toda posibilidad de perdonar. En otras palabras, si la reparación depende del perdón y el perdón no es una posibilidad en un mundo humano agredido y erosionado, todo intento de salir del círculo de la violencia está condenado al fracaso.

Pues bien, el enfoque restaurativo de la justicia apuesta por la figura del perdón, pero debe hacerlo en el marco de la construcción de un mundo moral compartido digno de confianza y esperanza. Se trata de trabajar cooperativamente por construir reservas de sentido para afianzar relaciones interpersonales moralmente adecuadas (Walker, 2006b). En sentido estricto, un enfoque restaurativo, consideramos, no deberá plantear medidas orientados al perdón como un acto performativo entre agresor y víctima, sino dirigidas a construir un mundo humano donde el perdón pueda volver a ser una posibilidad humana.

En efecto, el perdón concebido exclusivamente como un acto lingüístico entre agresor y víctima es un gesto valioso simbólicamente, pero que puede encerrar algunos peligros de no estar enmarcado en trabajos cooperativos más amplios que subsanen las relaciones morales defectuosas que dieron origen al daño atroz. Por ejemplo, si el perdón no está acompañado de un horizonte moral que permita comprender el daño como mal, se puede correr el riesgo de disminuir la gravedad de la injuria. De otro lado, si el perdón no se produce en el marco del reconocimiento pleno de la víctima, quienes han sufrido podrían perder la posibilidad de recuperar su identidad y sentido de autorrespeto. En este orden de ideas, el perdón es valioso, siempre que surja y sea parte de un mundo compartido de relaciones moralmente adecuadas, esto es siguiendo a Walker (2006b), un mundo en el cual podamos restaurar o crear estándares normativos que sean dignos de confianza y en donde se confíe en nuestras posibilidades humanas de corregir o hacer frente al daño; un mundo en que se puede compartir la esperanza de que los 
otros y nosotros mismos somos dignos de esa confianza. En un mundo moral con dichas cualidades, el valor del perdón no está en que suceda efectivamente, sino en que aparezca nuevamente como una posibilidad para la víctima, el agresor y la comunidad.

Desde esta perspectiva, retomando la distinción derridiana con la que se comenzó, entre un perdón condicionado e incondicionado, se tendría que reconocer que el perdón que pretende ser una salida al daño atroz siempre es condicionado. Siempre que por ello se entienda que el perdón moralmente reparador no consiste exclusivamente en el acto performativo de pedir perdón, en el simple olvido o dejar pasar la ofensa, sino que el perdón valioso es aquel que reafirma la confianza en los valores y estándares morales compartidos, así como la esperanza en nuestro mutuo entendimiento moral. Si no obedece a dichas condiciones en un escenario de daño atroz, entonces bien se puede hablar de un perdón inmoral, es decir, que perpetúa relaciones morales defectuosas.

Ahora bien, un enfoque restaurativo atiende a una serie de tareas para sentar las bases de una reparación moral que permita hacia el futuro relaciones moralmente adecuadas. Es en el marco de estas tareas donde la figura del perdón, junto con otras muchas virtudes y prácticas, debe aparecer dotada de unas ciertas características. Desde la perspectiva de Walker y otros autores que se mencionarán, seis son las tareas de la reparación moral. Veamos (Walker, 2006b, p. 28).

1. Abordar y reconocer el daño. Como señala Corbí (2012), nuestra reacción natural frente al daño es su negación. La aparición del daño significa, tanto para la víctima como para la comunidad, que la relación de hospitalidad que sostenemos con nuestro mundo en virtud del cual lo habitamos como si se tratara de nuestro hogar, es ya imposible. De allí que, advierte el autor, existe una tendencia a no dar crédito al daño ocurrido, más bien se le considera como una mera ilusión o como un mundo distinto al que no pertenece nuestro mundo humano. Al respecto, analiza los testimonios recopilados por Svetlana Alexievich de los soldados soviéticos en la guerra de Afganistán entre 1979-1989. La experiencia del soldado es significativa, señala, porque revela ese efecto del daño de dividir el mundo entre aquel espacio habitable en el que se afianzan nuestras expectativas y confianza más íntimas 
(homely world) y el mundo como campo de batalla donde todas las seguridades y protecciones son negadas. En efecto, para el soldado el campo de batalla difícilmente puede ser considerado el mundo real, pues la atrocidad y la tortura no tienen sentido desde el punto de vista del mundo como hogar: es la experiencia última del sinsentido y de lo inexplicable. Esta división entre el mundo real (hogar) y el mundo del campo (la ilusión) también tiene el efecto de quebrantar la identidad; quien está expuesto a la vulneración extrema no puede sostener al mismo tiempo un yo que habita un mundo familiar y seguro. Son experiencias tan profundamente opuestas que el yo del mundo conocido, confiable y seguro no puede sobrevivir una vez su vida transcurra en un mundo desprovisto de toda humanidad. También para quienes permanecen fuera del campo de batalla, el daño adquiere un carácter de mera ilusión, son incapaces de prestar atención a las historias del soldado sobreviviente; tal vez escuchen y conmemoren los eventos, pero no serán capaces de dejar que sus vidas se transformen o alteren por lo sucedido. En parte, ello se debe a que aceptar lo sucedido exige atribuir responsabilidades compartidas; en parte, a la necesidad de seguir haciendo del mundo un lugar confiable. Por supuesto, el soldado sobreviviente, quien carga en su cuerpo y en su memoria los horrores del daño, necesita que los demás den crédito de lo sucedido, requiere que los otros reconozcan que sus sentimientos embargados por la incertidumbre, decepción y angustia de vivir un mundo hostil e inseguro están justificados y no son una actitud patológica e irracional (Corbí, 2012).

Por la experiencia del soldado podemos inferir que el daño puede caer en la pérdida de significación. Como consecuencia, las posibilidades de fijar responsabilidades y maneras de corrección o compensación frente al mismo son seriamente obstaculizadas; pues si no existe reconocimiento del daño y de la complejidad de su significación, resulta imposible reafirmar el estatus moral de la víctima y articular nuevos compromisos que permitan pensar en un futuro distinto.

No obstante, con los esfuerzos de reconocimiento que la sociedad, el Estado y los perpetradores emprendan deben tomarse ciertas precauciones. Existen grados deficientes de reconocimiento. Un reconocimiento que oscile entre la justificación y la excusa no puede sentar las bases para superar el miedo, la angustia y el odio. El reconocimiento 
para ser moralmente reparador tendrá que ser ocasión para enjuiciar los hechos como inmerecidos, injustos e inexcusables, así como oportunidad para expresar garantías de no repetición (Govier, 2006).

La tarea del reconocimiento de los daños nunca estará plenamente finalizada. Un aspecto crucial del reconocimiento es exponer las constantes reinterpretaciones y resignificaciones de los daños. El paso del tiempo puede acrecentar nuestra comprensión de lo sucedido, pero también puede erosionarla devastadoramente. Por ello, el reconocimiento nunca está plenamente alcanzado, sino que requiere de constantes trabajos colaborativos de reinterpretación.

2. Señalar las responsabilidades. Nuestra comprensión habitual del daño casi siempre es dicotómica, consideramos que solo involucra a la víctima y al victimario. Al respecto, Trudy Govier (2006) considera que dicho lenguaje dicotómico resulta insuficiente, pues desconoce la complejidad de las relaciones que se afectan por el daño y la complejidad de los hechos de extrema violencia.

En casos como el colombiano, ello resulta particularmente cierto; tras una guerra de cincuenta años, víctimas y victimarios se empiezan a traslapar, aparecen victimarios que no son combatientes y las víctimas se multiplican ya sea por causa directa de la guerra o por sus efectos. En dichos escenarios, Govier (2006) considera que es necesario reconocer grados de victimización y perpetración. En la orilla de las víctimas, se podrían identificar las primarias, aquellas que directamente sufrieron el daño, y las secundarias, que serían familiares y allegados de las víctimas primarias. Igualmente, se podrían establecer víctimas terciarias, que serían las comunidades que se ven privadas de sus miembros y amenazadas por el terror de la violencia.

De la orilla de la perpetración también se pueden fijar niveles y, por tanto, responsabilidades distintas. Estarían, primero, los participantes directos del conflicto, los combatientes o quienes infligen los daños a través de la violencia física directa. En este mismo nivel se encontrarían los líderes e instigadores de los crímenes. Luego, se podrían reconocer los participantes secundarios que sin empuñar las armas o liderar grupos se sienten identificados, aprueban y contribuyen a las actividades de los perpetradores. Por último, se encontrarían los 
participantes terciarios que serían aquellas comunidades que justifican los medios violentos de los perpetradores. Estos últimos son indispensables para que el daño adquiera dimensiones de atrocidad, como se mencionó, la atrocidad real ocurre cuando el mundo está desprovisto de personas que sean dignas de confianza; dicha expectativa empieza a desaparecer cuando quienes no están involucrados directamente en los hechos violentos pierden su capacidad para intervenir o impedir el daño. Todos estos participantes tienen una responsabilidad compartida, aunque distinta en cada caso.

En el conflicto podrían encontrarse, advierte Govier, observadores neutrales que no participaron en ningún de los grados mencionados. Aunque cierto, consideramos que una de las fortalezas del enfoque restaurativo es su concepción de las responsabilidades ampliadas; es decir, que debe existir un esfuerzo común de individuos y comunidades para involucrarse activamente en procesos de reparación. Desde esta perspectiva, el observador neutral no tendría responsabilidad del daño, pero sí frente al daño.

\section{Restaurar o instaurar estándares morales que sean compartidos y} gocen de autoridad. Sobre este punto es particularmente sensible el enfoque restaurativo de la justicia en contraposición con la concepción correctiva de la justicia. Para esta última, según se dijo en el primer apartado, el daño se repara corrigiendo la desviación en el cumplimiento de principios y derechos. Pero desconoce que los daños graves muchas veces son producto de principios y derechos viciados, injustos o insatisfactorios. En este orden de ideas, cuando la justicia correctiva pretende restablecer un estado anterior al daño, puede incluso agudizar la vulneración y sufrimiento de las víctimas (Walker, 2006b).

Pensemos en un caso como el colombiano, en donde un factor definitorio de sus múltiples círculos de violencia ha sido la legal y legítima mala distribución de las tierras. Hacer justicia a desplazados y víctimas directas de los grupos al margen de la ley no puede significar simplemente suspender las acciones armadas de dichos grupos para que la gente pueda retornar a zonas rurales miserables e improductivas. Al contrario, reparar a las víctimas deberá implicar redefinir los derechos y principios que rigen la distribución de las tierras y las riquezas. 
Por tanto, la reparación moral exige replantear o crear estándares morales que respondan a las reclamaciones válidas y razonables de las víctimas. La centralidad de la víctima y su autoridad para participar en la redefinición del entendimiento moral de la comunidad son indispensables para articular plenamente la significación del daño e integrar plenamente a las instituciones, una perspectiva más incluyente de la justicia.

De otro lado, aparece la cuestión de la autoridad de las normas: ‘cómo respetar acuerdos normativos que alguna vez han sido violados? Apenas se vislumbran alternativas. Walker (2006b) considera que es esencial fortalecer el respeto por las normas a través de comunidades de enjuiciamiento; se trataría de comunidades que integran a las narrativas definitorias de su identidad, los valores y estándares morales que definen los alcances y límites de lo aceptado y prohibido por dicha comunidad.

4. Restaurar o crear la confianza que los individuos tienen en los estándares morales compartidos y su capacidad para responder y cuidar de esos acuerdos normativos.

5. Restaurar o instaurar la esperanza en las expectativas morales y en que sus responsables son dignos de confianza. Los puntos 4 y 5 merecen un tratamiento conjunto por tratarse del cultivo de dos virtudes fundamentales en la reparación moral: confianza y esperanza. Confiar en nuestra capacidad para acordar y respetar los términos de nuestro entendimiento moral, esperanza y confianza en los otros y en nosotros mismos. Como se mencionó, con el daño atroz se pierden dos expectativas normativas fundamentales que nos permiten funcionar normalmente en la vida cotidiana; la primera, la confianza en que nadie nos hará daño y la segunda, que si alguien lo hiciera un tercer agente vendría en nuestra ayuda. Podemos comprender que exista el daño y que en algunos casos esté justificado, pero no podemos considerarlo como inmerecido. El daño atroz quiebra dichas expectativas, arrojando a la víctima a un mundo indiferente.

La sensación de que nuestro mundo moral está desprovisto de toda realidad objetiva parece ser la consecuencia irreparable del daño. ¿Acaso podemos superar esta orfandad de mundo moral? Nuestro sentido de indignación y resentimiento frente al daño nos pone de presente que las 
reservas de sentido y valor no están agotadas. De allí, la importancia de los puntos precedentes para reafirmar la confianza y la esperanza en la autoridad de nuestros acuerdos morales. Responder al daño a través de su enjuiciamiento, de la aceptación de las responsabilidades, de la rendición de cuentas, del reconocimiento, de los esfuerzos de corrección, todos son parte fundamental para hacer circular nuevamente la confianza y la esperanza en nuestro mundo moral; así como el fortalecimiento de las instituciones, de los mecanismos del derecho y de la participación política.

\section{Restablecer o instaurar las relaciones entre las víctimas y los agresores,} entre las víctimas, los agresores y las comunidades. Generalmente, en este punto es donde aparece la figura del perdón. En efecto, el carácter relacional del perdón es un elemento recurrente en las reflexiones sobre el mismo (Walker, 2006b). En líneas generales, esta concepción sobre el perdón apuntaría a entenderlo como el restablecimiento de las relaciones entre el agresor y el ofendido en virtud del arrepentimiento y el resentir de la acción incorrecta que el agresor expresa, de la promesa del agresor de adoptar un comportamiento distinto, de la renuncia que la víctima haría de la venganza y, en últimas, del resentimiento que despierta la injuria y de la capacidad del ofendido de ver al ofensor bajo una nueva luz.

Visto así, en el perdón existe un tipo de transformación de agresor y víctima: la víctima renuncia a tomar como motivo de su acción futura hacia el agresor, la venganza, el odio y el resentimiento, para aceptarlo como una persona moral capaz de cambio. Del lado del agresor, la transformación consistiría en arrepentirse y corregir el daño causado. El resultado sería la restitución de la relación entre agresor y víctima como sujetos con valía moral, vale decir, las concepciones del perdón que abordan el carácter relacional.

Bajo una concepción del perdón como la someramente expuesta se puede comprender el lugar prioritario que actualmente ocupa el perdón en las propuestas de reconciliación. La presencia social del perdón interpersonal como restitución de las relaciones implica que la superación de la violencia y el daño es más que un mero modus vivendi en el que habitan agresores y víctimas. La sociedad reconciliada liberaría al futuro de las consecuencias nefastas y permanentes del daño; esto es, de la decepción, la angustia, la venganza, la recriminación y la culpa. 
Sin duda, el perdón interpersonal es valioso para la comunidad política, pero es necesario insistir nuevamente en que en el escenario de daño atroz se ve seriamente obstruido o impedido. Por ello, se requiere su encuadre en el marco más amplio de la reparación moral. Por lo dicho hasta aquí, ese marco implica procesos colaborativos por abordar y reconocer el daño, procesos amplios de asunción de responsabilidades compartidas, procesos de instauración de la confianza y la esperanza en nuestros acuerdos y entendimientos normativos, procesos que tiendan a definir relaciones morales ajustadas a la dignidad del ser humano. La finalidad de dichos procesos no es el perdón, podría ser que nunca ocurra entre víctima y agresor; más bien el objetivo es que el perdón reaparezca como una posibilidad.

Ahora bien, si el perdón aparece nuevamente en la escena moral, es necesario que fortalezca los procesos de reparación moral; según se dijo, no todas las experiencias de perdón tenderán a plantear o redefinir mejor los términos de la relación moral. Por ejemplo, la condonación y la excusa son formas insatisfactorias de perdón pues no tienen un carácter reparativo. En aquellas no tiene lugar el reconocimiento del estatus y autoridad de la víctima, ocurren de manera unilateral, se limitan a expresar simpatía por la víctima, pero justificando lo injustificado de la injuria; pueden significar el simple olvido de la ofensa a nombre de la pacificación o armonía social (Gamboa, 2002).

En la propuesta de Griswold, se encuentran varios criterios del perdón que consideramos buenos candidatos para pensar un perdón reparativo. Los criterios bien entendidos no se refieren a pasos que se deben cumplir para lograr un perdón exitoso, tampoco como recomendaciones de un programa terapéutico para lograr la paz interna, igualmente, no se proponen para juzgar la autenticidad de la petición o el otorgamiento del perdón. A nuestro juicio, dicho criterios interesan porque muestran el trabajo moral que requiere el perdón para diferenciarlo de una política del buen corazón. Según Griswold (2007), en primer lugar, del lado del ofensor se requiere:

1. Demostrar que no se quiere permanecer como el autor del mal causado.

2. Repudiar los agravios, injurias, crímenes y daños cometidos.

3. El agresor debe expresar arrepentimiento por el daño cometido. 
4. Expresar el compromiso de no incurrir nuevamente en la falta.

5. Comprender el daño desde la perspectiva de la persona injuriada o en otras palabras comprender cómo afecta el daño a la persona ofendida.

6. Ofrecer razones y la verdad del mal ocurrido.

Por su parte del lado del ofendido, propone:

1. Renunciar a la venganza.

2. Moderar el resentimiento.

3. Compromiso hacia el futuro de abandonar el resentimiento.

4. Ver al ofensor bajo una nueva comprensión que no esté sujeta al mal causado.

5. Comprenderse a sí mismo bajo una nueva narrativa que abandone tanto la inferioridad o humillación que causa el daño, como la superioridad frente al ofensor arrepentido.

6. La expresión explicita del perdón otorgado.

Cada uno de estos criterios merecería una reflexión de sus supuestos y alcances; no obstante, solo nos limitaremos a destacar dos aspectos. Primero, el momento privilegiado que tiene el reconocimiento y la comprensión del daño nos permiten considerar que cumple con las exigencias de un proceso de reparación moral. Segundo, es muy claro desde esta perspectiva el carácter relacional y cooperativo del perdón que ocurre en virtud de esfuerzos y riesgos tanto del ofendido como del ofensor.

Sin embargo, tenemos dos desacuerdos fundamentales. Primero, la centralidad que Griswold otorga al acto performativo del perdón puede llegar a eclipsar que el perdón como acto no es el comienzo o el objetivo de los procesos de reparación. Al contrario, el perdón se convertirá en una posibilidad siempre que otros trabajos morales interpersonales y sociales de reparación abonen el terreno. Pero, además, puede que el perdón efectivo nunca ocurra y es importante trasmitir a las víctimas que no están en la obligación de hacerlo. Segundo, si bien es cierto que el perdón es un proceso que corresponde a víctima y victimario, la injuria o el daño atroz no es una cuestión privada, sino que generalmente implica una tarea reparativa de toda la comunidad, especialmente, en los casos en que las verdaderas víctimas están ausentes (Walker, 2006b). 
En este aspecto, consideramos que un perdón reparador deberá incluir las acciones que emprende una comunidad para responder a la reparación moral de sus miembros.

\section{A modo de conclusión}

La discusión en torno a la relación entre el perdón y la esfera jurídico-política está cercada de difíciles aporías. No obstante, la pregunta por cómo hacerse cargo del daño es una cuestión irrenunciable para una comunidad política, pues el ser en común de lo político no puede permanecer indiferente una vez ha sido herido de muerte con la ocurrencia de lo atroz. Por supuesto, responder al daño exige replantear los contornos de la esfera jurídico-política. Aparecen tareas que generalmente desbordan sus límites, como los trabajos cooperativos para restablecer la confianza y la esperanza, al igual que tareas más próximas como la de replantear los términos normativos. De cualquier manera se puede afirmar que se trata de comprometer a los miembros de una sociedad con los trabajos cooperativos de la reparación moral.

En nuestro país, por lo que a esta investigación se refiere, las prácticas de perdón han merecido casi en exclusivo una atención mediática, son escasas las investigaciones en torno los lenguajes del perdón, las formas en que las víctimas asumen o rechazan las peticiones, la manera en que los jueces interpretan la incorporación en la ley de la figura del perdón o de la disculpa. Igualmente, se observa la tendencia a concentrarse en las peticiones explícitas descuidando otros modos de la reparación. Como se señaló en el presente texto, el perdón puede ser una posibilidad valiosa siempre que se fortalezca la integralidad de los procesos de reparación moral.

\section{Referencias}

Arendt, H. (1958). Human condition. Chicago: Chicago University Press.

Card, C. F. (2002). The atrocity paradigm: A theory of evil. Oxford: Oxford University Press. 
Carse, A. L., \& Tirrell, L. (2010). Forgiving grave wrongs. En C. Allers \& M. Smit (Eds.), Forgiveness in perspective (pp. 43-65). Amsterdam: Rodopi Press.

Corbí, J. E. (2012). Morality, self-knowledge, and human suffering. London: Routledge.

De Greiff, P. (2006). Justice and reparations. En P. de Greiff (Ed.), Handbook of reparations (p. 457). Nueva York: Oxford University Press.

Derrida, J. (2003). El siglo y el perdón. Buenos Aires: De la Flor Ediciones.

Gamboa, C. (2002). Ética del perdón. En A. Chaparro (Comp.), Cultura política y perdón (pp. 148-159). Bogotá: Editorial Universidad del Rosario. Recuperado de http://datateca.unad.edu.co/contenidos/753003/Cap._12_ La_etica_del_perdon.pdf

Griswold, C. (2007). Forgiveness: A philosophical exploration. Cambridge, MA: Cambridge University Press.

Govier, T. (2006). The apology initiative. En E. Barkan \& A. Karn (Eds.), Taking wrongs seriously: Apologies and reconciliation (pp.67-88). Nueva York: Humanity Books.

Heidegger, M. (1927). Ser y tiempo (Trad. J. E. Rivera). Sección primera. Trabajo original publicado en 1927). Recuperado de https://espanol. free-ebooks.net/ebook/Ser-y-el-Tiempo/pdf?dl\&preview

Jankélévitch, V. (1996). ¿Should we pardon them? Critical Inquiry, 22(3), 552 572. Recuperado de http://www.jstor.org/stable/1344023

Lefranc, S. (2005). Políticas del perdón. Bogotá: Norma.

Margalit, A. (2004). The ethics of memory. Cambridge, MA: Harvard University Press.

Mèlich, J. -C. (2012). Paradojas. (Una nota sobre el perdón y la finitud). Ars Brevis, 18, 122-134.

Philpott, D. (2012). Just and unjust peace. An ethic of political reconciliation. Oxford: Oxford University Press.

Teitel, R. (2003). Genealogía de la justicia transicional. Harvard Human Rights Journal, 16, 69-94.

Walker, M. U. (2006a). Restorative justice and reparations. Journal of Social Philosophy, 7(3), 377-395.

Walker, M. U. (2006b). Moral repair: Reconstructing moral relations after wrongdoing. Cambridge, MA: Cambridge University Press. 
EL PERDÓN: DIFÍCIL POSIBILIDAD

Wiesenthal, S. (1969). The sunflower: On the possibilities and limits of forgiveness. Nueva York: Schocken Books.

Zubiri, X. (2006). Tres dimensiones sociales del hombre, individual, social, histórica. Madrid: Alianza. 